\title{
Timely initiation of complementary feeding practice and associated factors among mothers of children aged from 6 to 24 months in Axum town, north Ethiopia
}

\author{
Samson Yemane ${ }^{1}$, Tadesse Awoke ${ }^{2}$, Measho Gebreslassie ${ }^{3}$ \\ ${ }^{1}$ Department of Human Nutrition, Institute of Public Health, University of Gondar, Gondar, Ethiopia \\ ${ }^{2}$ Department of Epidemiology and Biostatistics, Institute of Public Health, University of Gondar, Gondar, Ethiopia \\ ${ }^{3}$ Department of Health Service Management and Health Economics, Institute of Public Health, College of Medicine and Health Sciences, \\ University of Gondar, Ethiopia
}

Email address:

yemanesamson@yahoo.com (S. Yemane), tawoke7@gmail.com (T. Awoke), measho2013@gmail.com (M. Gebreslassie)

\section{To cite this article:}

Samson Yemane, Tadesse Awoke, Measho Gebreslassie. Timely Initiation of Complementary Feeding Practice and Associated Factors among Mothers of Children Aged from 6 to 24 Months in Axum Town, North Ethiopia. International Journal of Nutrition and Food Sciences. Vol. 3, No. 5, 2014, pp. 438-442. doi: 10.11648/j.ijnfs.20140305.21

\begin{abstract}
Introduction: Appropriate complementary feeding is critical for the achievement of a healthy growth and development and mere survival of young children. Lack of appropriate breast-feeding and complementary feeding practice are the main cause of under nutrition. An estimated $32 \%$ of children under five years in developing countries are stunted and $10 \%$ are wasted. Objective: To assess timely initiation of complementary feeding practice and associated factors among mothers of children aged from 6 to 24 months living in Axum town, North Ethiopia. Methods: Community based crosssectional study was conducted from April to May 2013. A sample of 422 subjects was selected by using systematic random sampling technique. Data were collected using pre-tested interviewer administered structured questionnaires. The data were cleaned, coded, entered in to EPI-INFO version 3.5.1, and transferred and analysed using SPSS version 20. Results: Out of 422 study participants, $223(52.8 \%)$ have started complementary feeding practices to their child timely. Married women [AOR $=2.490 ; 95 \% \mathrm{CI}:(1.170,5.301)]$ and attended ANC follow up $[\mathrm{AOR}=3.874 ; 95 \%$ CI: $(1.805,8.314)]$ were positively associated with timely initiation of complementary feeding. On the other hand, mothers whose husband cannot read and write $[\mathrm{AOR}=0.358 ; 95 \% \mathrm{CI}:(0.148,0.863)]$, household size of $4-6(\mathrm{AOR}=0.34 ; 95 \% \mathrm{CI}: 0.16,0.74)$ and mothers who delivered at home $(\mathrm{AOR}=0.338 ; 95 \% \mathrm{CI}: 0.12,0.99)$ were negatively associated with timely initiation of complementary feeding. Conclusion and recommendation: Timely initiation of complementary feeding practice was relatively low in the study area. Mother's marital status, husband education, family size, mother's ANC follow-up, and mother's place of delivery were significantly associated with timely initiation of complementary feeding. Nutritional counseling, promoting ANC follow up, nutrition education \& enhancing institution delivery were recommended to the concerned bodies.
\end{abstract}

Keywords: Complementary Feeding, Timely Initiation, Practice, Axum Town

\section{Introduction}

Sub-optimal breast feeding and poor complementary feeding practices leads to mal-nutrition, which is the single biggest contributor to child mortality and the underlying causes of more than half of all deaths among children 6-59 months age (1).

The period from birth to two years of age is the "critical window" for the promotion of optimal growth, health and development of a child, because it is during this period that children are particularly vulnerable to growth retardation, micro-nutrient deficiencies, and common childhood illnesses $(2,3)$.

The achievement of universal coverage of optimal breast feeding could prevent $13 \%$ of deaths occurring in underfive years children globally. While, appropriate complementary feeding practice would result in an additional $6 \%$ reduction in under-five mortality (4).

Around $50 \%$ children under five years of age die due to preventable causes of mal-nutrition and $99 \%$ of them were 
found in the developing world, particularly in sub-Saharan Africa. About 9\% of sub-Saharan Africa children had MAM and $2 \%$ of children in developing countries had SAM (5).

In Ethiopia, mal-nutrition is the underlying causes of child morbidity and mortality, which contributes for more than $57 \%$ of deaths in under five years children. According to EDHS 2011report, $10 \%$ of under five children had sever and moderate acute malnutrition and $29 \%$ of children were under weight for their age. The proportion of children with acute malnutrition in Tigray was $10 \%$, and $35 \%$ of children were under weight, which is higher than national figure.

Breast feeding is universal in Ethiopia, however only 52\% of children under 6 months were exclusively breastfeed. In addition to breast milk, $19 \%$ of infants under 6 months were given plain water, While $10 \%$ of infant under 6 months were given complementary foods. In Tigray, 35\% of mothers initiated breastfeeding to their new born immediately after delivery and $67 \%$ of mothers gave the first milk within 3 days $(6,7,8,9)$.

Hence, this study was aimed to assess the magnitude of timely initiation of complementary feeding and factors associated with it.

\section{Methods}

The study was carried out in Axum town from April to May 2013. Axum is located in the Central zone of Tigray Regional State, $270 \mathrm{KM}$ away from Mekelle (the capital city of Tigray). Axum is one of the ancient and historical tourist destination towns with several archaeological and ethnographic museums. The study utilized communitybased cross-sectional study design with quantitative data collection method. Mothers having children from 6 to 24 months of age were selected by using systematic random sampling technique. Mothers who were seriously ill and unable to respond were excluded from the study.

The sample size was calculated using single population proportion formula with the following assumptions; proportion $50 \%$, margin of error $5 \%$ and $95 \%$ confidence level. The sample size was 422 after considering 10\% non response rate. The total sample size was allocated proportionally to all kebeles. The dependant variable was timely initiation of complementary feeding practice; likewise the independent variables included were socio demographic factors, nutritional related factors and health care related factors.

The questionnaires were adapted from WHO standard questions to suit the study setting (2). Pre- test was done on $10 \%$ of similar subjects at Adwa town. Data were collected using pre-tested, pre-coded and interviewer-administered questionnaires. The collected data were cleaned, coded, entered into EPI-INFO version 3.5.1 software and transferred and analysed using SPSS version 20. Bivariable analysis was done and variables with p-value less than 0.2 were included in the multiple logistic regression analysis. Odds ratio and 95\% confidence intervals were also computed along with the corresponding p-value.

\section{Results}

Table 1. Socio-demographic characteristics of the study participants, Axum, Ethiopia 2013

\begin{tabular}{|c|c|c|}
\hline Characteristics & Frequency & Percent (\%) \\
\hline \multicolumn{3}{|l|}{ Age of mother(in years) } \\
\hline $15-19$ & 12 & 2.8 \\
\hline $20-25$ & 141 & 33.4 \\
\hline $26-29$ & 107 & 25.4 \\
\hline$>=30$ & 162 & 38.4 \\
\hline \multicolumn{3}{|l|}{ Age of child(in months) } \\
\hline $6-10$ & 90 & 21.3 \\
\hline $11-15$ & 143 & 33.9 \\
\hline $16-20$ & 123 & 29.1 \\
\hline 21- 24 & 66 & 15.6 \\
\hline \multicolumn{3}{|l|}{ Sex of child } \\
\hline Male & 223 & 52.8 \\
\hline Female & 199 & 47.2 \\
\hline \multicolumn{3}{|c|}{ Relation to the head of household } \\
\hline House wife & 365 & 86.5 \\
\hline Daughter & 11 & 2.6 \\
\hline House maid & 3 & 0.7 \\
\hline Head of household & 43 & 10.2 \\
\hline \multicolumn{3}{|l|}{ Religion } \\
\hline Orthodox & 366 & 86.7 \\
\hline Muslim & 56 & 13.3 \\
\hline \multicolumn{3}{|l|}{ Ethnicity } \\
\hline Tigreway & 419 & 99.3 \\
\hline Others & 3 & 0.7 \\
\hline \multicolumn{3}{|c|}{ Mother Educational status } \\
\hline Can't read \& write & 81 & 19.2 \\
\hline Read \& write only & 71 & 16.8 \\
\hline $1-8$ & 102 & 24.2 \\
\hline $9-12$ & 137 & 32.5 \\
\hline Above high school & 31 & 7.3 \\
\hline \multicolumn{3}{|c|}{ Husband educational status } \\
\hline Can't read \& write & 39 & 9.2 \\
\hline Read \& write only & 90 & 21.3 \\
\hline $1-8$ & 111 & 26.3 \\
\hline $9-12$ & 110 & 26.1 \\
\hline Above high school & 72 & 17.1 \\
\hline \multicolumn{3}{|l|}{ Family size } \\
\hline $1-3$ & 134 & 31.8 \\
\hline $4-6$ & 249 & 59.0 \\
\hline $7-10$ & 39 & 9.2 \\
\hline \multicolumn{3}{|c|}{ Number of under five children } \\
\hline One & 204 & 48.3 \\
\hline Two & 134 & 31.8 \\
\hline Three & 84 & 19.9 \\
\hline \multicolumn{3}{|l|}{ Marital status } \\
\hline Unmarried & 11 & 2.6 \\
\hline Married & 367 & 87.0 \\
\hline Other ${ }^{*}$ & 44 & 10.4 \\
\hline \multicolumn{3}{|c|}{ Mother current occupational status } \\
\hline House wife & 301 & 71.3 \\
\hline Private business & 61 & 14.5 \\
\hline Student & 7 & 1.7 \\
\hline Government employed & 19 & 4.5 \\
\hline Others $* *$ & 34 & 8.1 \\
\hline \multicolumn{3}{|c|}{ Husband occupational status } \\
\hline Government employed & 107 & 25.4 \\
\hline Private business & 281 & 66.6 \\
\hline Unemployed & 34 & 8.1 \\
\hline
\end{tabular}

The study was reviewed and approved by Institution Research Review Boards; Institute of Public Health at the University of Gondar and official letter of co-operation was 
also obtained from Axum Woreda Health Office. The purpose and the importance of the study were explained and written consent was obtained from each participant. Moreover, confidentiality of the information was assured by using anonymous questionnaires and keeping the data in a secured place.

A total of 422 mothers were participated in the study with response rate of $100 \%$. The mean age of mothers was 28 with \pm 5.39 SD and the mean age of the child was 14.7 months with \pm 5.439 SD. Majority of the respondents were orthodox Christianity followers $(86.7 \%)$ and Tigreway in ethnicity (99.3\%) (table1).

\section{Health Care Related Characteristics of the Respondents}

Among the study subjects, $382(90.5 \%)$ and $361(86 \%)$ reported that they had history of antenatal and postnatal follow up respectively. Moreover, 402 (95.3\%) of the study participants gave birth in health institutions and $99.1 \%$ of them were found to have good knowledge of timely initiation of complementary feeding (table 2).
Table 2. Health care related factors of the respondent, Axum, Ethiopia 2013

\begin{tabular}{lll}
\hline Characteristics & Frequency & Percent \\
\hline Antenatal follow up & & \\
Yes & 382 & 90.5 \\
No & 40 & 9.5 \\
Postnatal visit & & \\
Yes & 361 & 85.5 \\
No & 61 & 14.5 \\
Delivery service & & \\
Health institution & 402 & 95.3 \\
Home & 20 & 4.7 \\
Knowledge of complementary feed & & \\
Yes & 418 & 99.1 \\
No & 4 & 0.9 \\
\hline
\end{tabular}

\subsection{Timely Initiation of Complementary Feeding}

The prevalence of timely initiation of complementary feeding in the study area was $52.8 \%$. Of them, $181(81.2 \%)$ mothers provided mashed food or fluid to their child. In addition, half of mothers who initiated complementary feeding timely used cow or powder milk and bottle nipple to feed their child.

Table 3. Bivariate and multivariate logistic regression of selected variables with timely initiation of complementary feeding practice, Axum, Ethiopia, 2013

\begin{tabular}{|c|c|c|c|c|}
\hline \multirow{2}{*}{ Variables } & \multicolumn{2}{|c|}{ Timely initiation of complementary feeding practice } & \multirow{2}{*}{$\operatorname{COR}(95 \% \mathrm{CI})$} & \multirow{2}{*}{$\operatorname{AOR}(95 \% C I)$} \\
\hline & Yes & No & & \\
\hline \multicolumn{5}{|l|}{ Age of mother } \\
\hline $15-19$ & 7 & 5 & $1.207(0.368,3.961)$ & \\
\hline $20-25$ & 72 & 69 & $0.900(0.572,1.414)$ & \\
\hline $26-29$ & 57 & 50 & $0.983(0.602,1.603)$ & \\
\hline.$>=30$ & 87 & 75 & 1 & \\
\hline \multicolumn{5}{|l|}{ Mother educational status } \\
\hline Can't read \& write & 38 & 43 & $0.486(0.207,1.143)$ & \\
\hline Read \& write only & 31 & 40 & $0.426(0.178,1.020)$ & \\
\hline $1-8$ & 61 & 41 & $0.818(0.355,1.887)$ & \\
\hline $9-12$ & 73 & 64 & $0.627(0.279,1.408)$ & \\
\hline Above high school & 20 & 11 & 1 & \\
\hline \multicolumn{5}{|c|}{ Current mother occupation } \\
\hline House wife & 170 & 131 & $1.658(0.859,3.200)$ & \\
\hline Private business & 26 & 35 & $0.949(0.427,2.110)$ & \\
\hline Government employed & 9 & 10 & $1.150(0.386,3.426)$ & \\
\hline Others** & 18 & 23 & 1 & \\
\hline \multicolumn{5}{|c|}{ Husband Educational status } \\
\hline Can't read \& write & 17 & 22 & $0.363(0.162,0.810)$ & $0.358(0.148,0.863)$ \\
\hline Read \& write only & 34 & 56 & $0.285(0.148,0.548)$ & $0.232(0.116,0.463)$ \\
\hline Grade1 -8 & 73 & 38 & $0.902(0.479,1.696)$ & $0.919(0.477,1.772)$ \\
\hline Grade $9-12$ & 50 & 80 & $0.391(0.210,0.728)$ & $0.362(0.190,0.692)$ \\
\hline Above high school & 49 & 23 & 1 & 1 \\
\hline \multicolumn{5}{|l|}{ Husband occupation } \\
\hline Government employed & 57 & 50 & $1.282(0.592,2.779)$ & \\
\hline Private business & 150 & 131 & $1.288(0.631,2.628)$ & \\
\hline Unemployed & 16 & 18 & 1 & \\
\hline \multicolumn{5}{|c|}{ Number of under five children } \\
\hline One & 108 & 96 & $0.658(0.391,1.108)$ & \\
\hline Two & 62 & 72 & $0.504(0.288,0.880)$ & \\
\hline Three \& above & 53 & 31 & 1 & \\
\hline \multicolumn{5}{|l|}{ Family size } \\
\hline $1-3$ & 70 & 64 & $0.486(0.227,1.039)$ & $0.452(0.196,1.045)$ \\
\hline $4-6$ & 126 & 123 & $0.455(0.221,0.939)$ & $0.340(0.155,0.743)$ \\
\hline $7-10$ & 27 & 12 & 1 & 1 \\
\hline \multicolumn{5}{|l|}{ ANC follow-up } \\
\hline Yes & 211 & 171 & $2.879(1.422,5.831)$ & $3.874(1.805,8.314)$ \\
\hline
\end{tabular}




\begin{tabular}{|c|c|c|c|c|}
\hline \multirow{2}{*}{ Variables } & \multicolumn{2}{|c|}{ Timely initiation of complementary feeding practice } & \multirow{2}{*}{$\operatorname{COR}(95 \% \mathrm{CI})$} & \multirow{2}{*}{$\operatorname{AOR}(95 \% C I)$} \\
\hline & Yes & No & & \\
\hline No & 12 & 28 & 1 & 1 \\
\hline \multicolumn{5}{|l|}{ Place of delivery } \\
\hline Home & 6 & 14 & $0.365(0.138,0.970)$ & $0.338(0.115,0.989)$ \\
\hline Health institution & 217 & 185 & 1 & 1 \\
\hline \multicolumn{5}{|l|}{ Post natal follow up } \\
\hline Yes & 187 & 174 & $0.746(0.430,1.294)$ & \\
\hline No & 36 & 25 & 1 & \\
\hline
\end{tabular}

\subsection{Factors Associated with Timely Initiation of Complementary Feeding}

Both bivariate and multivariate analyses were done to identify the factors associated with timely initiation of complementary feeding. Accordingly; husband education status, number of under five children, ANC follow up, place of delivery and delivery service had significant association with the dependent variable at the bivariate analysis ( $p$-value $<0.05)$.

In multivariate analysis; husband education, family size, ANC follow up and place of delivery were significantly associated with timely initiation of complementary feeding.

Mothers whose husband cannot read and write were $64 \%$ times less likely to initiate timely complementary feeding than mothers whose husband attended high school and above $[\mathrm{AOR}=0.36 ; 95 \% \mathrm{CI}:(0.148,0.863)]$.

Furthermore, mothers who attended ANC follow up were 3.87 times more likely to initiate timely complementary feeding than whom did not attend $[\mathrm{AOR}=3.87 ; 95 \% \mathrm{CI}$ : $(1.805,8.314)]$. In addition, mothers who delivered at home were $66 \%$ times less likely to initiate timely complementary feeding than whom delivered at health institution $[\mathrm{AOR}=0.338$; 95\% CI: $(0.115,0.989)]$ (table 3).

\section{Discussion}

Our study revealed that the timely initiation of complementary feeding among mothers with children aged from 6-24 months was 52.8\% [95\% CI :( 48.08, 57.61)]. This finding is relatively lower than WHO recommendation for timely initiation of complementary feeding which is greater than or equal $80 \%(10)$. This finding was also lower than the study conducted in Nepal $70 \%$ (11), Bangladesh 71\% (12) Sirlanka 84\% (13), Senegal (69\%), Niger (78\%) and Chad (68\%). The observed difference might be due to low socio-economic status, poor infant and young child feeding practices, some cultural practices, and low of health care access in Ethiopia.

However, this finding is higher than studies conducted in Indonesia (12\%), Pakistan (39.2\%), Mauritania (40\%) and Mali (30\%). This could be due to lack of health access related to socio-economic and political crises in some of the mentioned countries.

On the other hand, this finding is in line with study done in; India (55.7\%) and Burkinfaso (50\%). Similarly, this finding is in line with studies done elsewhere in Ethiopia, Ethiopian Demographic and Health Survey 2011(51\%), and Harar $(54.4 \%)(6,14)$. This indicates that timely initiation of complementary feeding is low across the nation.

Mothers who had low educational status husband and small family size were less likely to initiate timely complementary feeding. This could be due to relatively high birth interval in the household may lead the mother to delay complementary feeding.

Mothers who had ANC follow up and delivered at health institution were more likely to initiate timely complementary feeding compared to their counterparts. This is similar to a study done in Harar, Ethiopia. This might be due to the fact that nutrition counseling and other services are provided at the ANC and delivery service. Similarly, this might be due to the fact that home deviled mothers would not have sufficient information about recommended child feeding practices and they are more influenced by communities' inappropriate child feeding practices such as pre-lacteal feeding and early initiation of complementary feeding.

Recall-bias during interview of the mothers could be the possible limitation of the study.

\section{Conclusion and Recommendation}

Timely initiation of complementary feeding among mothers who have children aged 6-24 months in Axum town was relatively low. Husband education, family size, mother's ANC follow-up and mother's place of delivery were significantly associated with timely initiation of complementary feeding.

Axum Woreda Health Office should promote rigorous ANC follow up and institution delivery. Health professionals who are involved in maternal health should provide nutrition education giving emphasis towards timely initiation of complementary feeding. Similarly, the health extension workers should provide nutrition counseling and promote timely initiation of complementary feeding practices in the region. Finally, researchers need to give emphasis on the impact of timely initiation of complementary feeding on child overall health by assessing the energy needed and consistency of feeding using analytical study designs.

\section{List of Abbreviations}

$\begin{array}{ll}\text { ANC } & \text { Ante Natal Care } \\ \text { AOR } & \text { Adjusted Odds Ratio } \\ \text { CI } & \text { Confidence Interval } \\ \text { EDHS } & \text { Ethiopian Demographic and Health Survey }\end{array}$


MAM

Mild Acute Malnutrition

SAM

SD

Sever Acute Malnutrition

WHO World Health Organization

\section{Acknowledgment}

We deeply express our gratefulness to Axum Town Health Office for their genuine cooperation and we would like to extend our special thanks and sincere appreciation to data collectors, supervisors and study participants.

\section{References}

[1] Peletier DL, Frongillo EA, Schroeder DG and Habicht JP. The effect of malnutrition no child mortality in developing countries. Bull World Health Organ 1995,73(4): 443-8

[2] WHO; Global Strategy for Infant and Young child feeding, Geneva; 2003

[3] Lowa wic program: breastfeeding promotion and support guideline for healthyfull term infant lowa department of public health August 2001.

[4] Gareth J, Richard WS, Robert EB, Zulfiqar AB, and Saul SM: How many child deaths can we prevent this year? Lancet 2003,362(9377):65-71

[5] Colline D, and Ytes, R. The need to update the classification of acute malnutrition. The lancet 2008, 4(362): 249-250.

[6] Ethiopian Demographic and Health Survey: Addis Ababa, Ethiopia; 2011.
[7] Alive and thrive baseline survey: report on IYCF practice, beliefs and influence in Tigray and SNNPR, Addis Ababa 2010 .

[8] Sinhababu A, Mukhopadhyay DK. Panja,TK, Saren AB, Mandal NK and Biswas AB: Infant and young child-feeding practice in Bankura district, west Bengal-India. Journal of health, population and nutrition 2010, 294-9.

[9] Federal Ministry of Health: Family Health Department, Ethiopia. National Strategy for infant and young child feeding 2004.

[10] World Health Organization: Infant and Young Child Feeding. A Tool for Assessing National Practices, Policies and Programs. Geneva 2003.

[11] Joshi N et al: Determinants of inappropriate complementary feeding practices in young children in Nepal. Secondary data analysis of Demographic and Health Survey 2006.

[12] Kabir.I et.al: Determinants of inappropriate complementary feeding practices in infant and young children in Bangladesh. Secondary data analysis of Demographic Health Survey 2007. Maternal and Child Nutrition 2012, 8 (1): 11-27 11 .

[13] Senarath U et al. Determinants of inappropriate complementary feeding practices in young children in Sri Lanka. Secondary data analysis of Demographic and Health Survey 2006-2007.

[14] Wuehler S.E., Hess SY. and Brown, KH: Accelerating improvements in nutritional and health status of young children in the Sahel region of Sub-Saharan Africa. Review of international guidelines on infant and young child feeding and nutrition: Maternal \& Child Nutrition 2011, 7: 6-34. 